Modalities of cosmopolitanism and mobility parental education strategies of global, immigrant and local middle-class Israelis Maxwell, Claire; Yemini, Miri

Published in:

Discourse

DOI:

10.1080/01596306.2019.1570613

Publication date:

2019

Document version

Peer reviewed version

Citation for published version (APA):

Maxwell, C., \& Yemini, M. (2019). Modalities of cosmopolitanism and mobility: parental education strategies of global, immigrant and local middle-class Israelis. Discourse, 2019(5), 616-632.

https://doi.org/10.1080/01596306.2019.1570613 
Modalities of cosmopolitanism and mobility: Parental education strategies of global, immigrant and local middle class Israelis

This paper is published in DISCOURSE: STUDIES IN THE CULTURAL POLITICS OF EDUCATION, online 24 January 2019.

https://www.tandfonline.com/doi/full/10.1080/01596306.2019.1570613

This is a pre-print (i.e. final draft pre-refereeing) version according to SHERPA/ROMEO (date: 30

September 2018)

Claire Maxwell

University of Copenhagen

Department of Sociology

Faculty of Social Sciences

Øster Farimagsgade 5, Bld. 16

DK - 1353 Copenhagen K

cm@soc.ku.dk 


\title{
Modalities of cosmopolitanism and mobility: Parental education strategies of global, immigrant and local middle class Israelis
}

Claire Maxwell \& Miri Yemini

\begin{abstract}
In this study we explore how different forms of family mobility shape parental education strategies of three middle class groups (moored Israeli professionals, immigrants from Israel to the UK and global middle class Israeli families). By focusing on families from the same nationality, we show how different practices of mobility differentiate between these middle class fractions. Building on Andreotti's framework for 'global mindedness' we suggest that orientations to cosmopolitanism also differentiate between these groups - from tourism (moored middle class), to empathy (immigrant middle class), to visiting (global middle class). By drawing on this conceptualisation, it is possible to understand why, despite the considerable uncertainty that constant mobility generates for children's education and futures, global middle class parents appear to assuredly navigate processes of securing and transmitting advantage.
\end{abstract}

Keywords: Global Middle Class, mobility, cosmopolitanism, global mindedness, Beck

\section{Introduction}

According to Beck (2012), we are living 'in an age of cosmopolitization' (p. 7), where all relations business, institutional, familial - have become enmeshed and interwoven, to the extent that there is 'no outside' or 'other' anymore (p. 9), at least for some social groups (Brown, 2010). In this era of 'second modernity' (p. 10), the structure of the nation-state therefore loses its salience as a mechanism for understanding relations. Beck (2007) challenges the practice of 'methodological nationalism' in thinking, by introducing a 'cosmopolitan sociology' where he seeks to dismiss state borders as natural units of analysis when considering key social questions. Beck's proposition aligns with the arguments made by Baumann (1998) about 'globals' who move fluidly around the world, and for whom notions of 'home' and 'belonging' are not tied to nations. While mobility nowadays is not restricted to social groups with resources - as the high levels of planned, forced, aspirational patterns of migration attest to (Scott, 2006) - the reasons for mobility and means available to facilitate such movement and settlement in new locations vary considerably. Our research focuses on understanding how the kinds of discursive, affective and economic resources various middle class groups possess and are able to activate (Vincent et al., 2012), intersects with their practices of mobility in a broader sense (Urry, 
2007), and may therefore distinguish between various fractions of the middle classes (Yemini \& Maxwell, 2018a; Yemini, Maxwell, \& Mizrachi, 2018).

In this paper we draw on interviews with 68 participants - highly-educated middle class professionals, all of Israeli origin - who are variously mobile. Our analysis specifically engages with the debate about the nature of the 'global middle classes' (GMC) (Ball \& Nikita, 2014; Yemini \& Maxwell, $2018 b$ ). We are interested in understanding whether and how practices of the so-called GMC might or might not be distinctive when compared to their other, perhaps more locally-moored, middle-class counterparts (Sheller \& Urry, 2006). We have decided to focus on middle class participants, so-defined because of their education level and professional employment orientations, who are of the same 'nationality'. This allows our analysis to specifically examine how differences in forms of mobility shape practices of parenting and education, affective belonging, surety, and cosmopolitanism.

In what follows, we introduce the concept of cosmopolitanism as we draw on it for this paper, integrating Andreotti et al.'s (2015) model of global mindedness in our discussions of the different orientations to cosmopolitanism. We also draw on Beck's (1992) notion of risk society when seeking to make sense of the ways participants conceived of the boundaries of space they occupy. Specifically, we consider how parents manage the 'uncertainty' that global mobility may throw up in managing their transcendence of national borders.

\section{Modalities of Cosmopolitanism}

For many, at least as an abstract concept, cosmopolitanism is about a positive and proactive engagement with the 'Other', that seeks to foster mutually respectful relations (Rizvi, 2005). However, it is a contested notion within scholarly writing (see Schiller \& Irving, 2014 for a review). It is sometimes presented as a central facet of modernity (Beck, 2012), and often imbued with the possibility of fostering relations of respect and understanding between groups (Gaudelli, 2016). Meanwhile, cosmopolitanism is also closely related to the level of uncertainty a person can psychically manage, and extent of stress and anxiety experienced when encountering different people, places and spaces (Beck, 2012).

The literature also emphasizes the emergence of cosmopolitanism as a desired orientation, which in turn is likely to lead to growing inequalities (Weenink, 2008) as access to such practices are determined by the ability to be mobile in particular ways. It is argued by many that such forms of cosmopolitanism are aligned with current geo-political relations of power, neo-colonial North-South divides, and local 
socio-economic inequalities (Appiah, 2006; Goren, Maxwell, \& Yemini, 2018; Hannerz, 2007). Within this latter conceptualisation, cosmopolitanism can therefore be understood as part of the class reproduction machinery - whether tethered to the nation state or a more global circuit of relations (Kenway et al., 2017). This articulation suggests that people approach the practice of cosmopolitanism in a more instrumental way, focusing on the acquisition of various capitals and a certain orientation such as the expectation of relatively free movement around the world, and the confidence to imagine oneself as having the credentials and skills to apply for professional positions that may be located almost anywhere around the globe.

In drawing on the concept of cosmopolitanism when researching the GMC, it is most likely to align with it being a form of (cultural) capital, which further privileges this group (Maxwell \& Aggleton, 2016). Yet, through mobility and openness to frequent relocation, the more humanistic interpretations of cosmopolitanism, or, in other words - global mindedness - might still inform the kinds of orientations articulated by the GMC. It is this tension, situated as a binary in much of the literature on cosmopolitanism, global citizenship education (Goren, Maxwell, \& Yemini, 2018), and studies of elite education (Kenway et al., 2017) that our study has sought to engage in. Can the GMC - who have access to different modalities of cosmopolitanism integrate these within their practices?

In this paper we take-up Andreotti et al.'s (2015) concept global mindedness to help us define the various modalities of cosmopolitanism. While Andreotti and colleagues' research grew out of the Finish context, they define global mindedness as a form of engagement with 'others and difference in contexts characterised by plurality, complexity, uncertainty, contingency and inequality' (Andreotti et al., 2015: 254), a definition we feel has saliency more broadly. Furthermore, such a description is similar to that offered by Beck's 'age of cosmopolitanization' and the kinds of everyday moments we live through in today's 'risk society'. Beck and Sznaider (2006) suggest our research agendas should not assume 'that humanity is naturally divided into a limited number of nations, which organize themselves internally as nation-states and externally set boundaries to distinguish themselves from other nation-states' (p. 57). Taking on board these starting positions, we follow Andreotti et al. (2015) who argue that global mindedness (or cosmopolitanism) is a set of dispositions, that denote 'embodied possibilities for action' (p. 255) which can be examined across geo-political borders. In particular, Andreotti et al. define three dispositions that usefully help us make sense of the differences between the parents in our study, as they occupy different middle class locations on the basis of the extent and type of mobilities that characterise their lives. Andreotti et al. (2015) identify three types of globalmindedness. 'Tourism', the first form, is associated with objectivism, where the world is seen in only 
one way. A second position taken is 'empathy', associated with relativism, where each individual is acknowledged as potentially holding different views and perspectives of the world, but people still understand others as different from him/her. The third type of global mindedness is that of 'visiting' which 'entails locating oneself in a different place, not with the ambition to think and feel like others in that place do, but to have one's own thoughts, feelings and experiences in a location that is different from one's own. A location where one is with and in the presence of others, exposed to the world, and open to being taught by unpredictable teachers and teachings' (p. 255). It is further suggested by Andreotti et al., that theoretically tourism would be connected with ethno-centrism, empathy with ethnorelativism and visiting with existentialism. In the analysis of our data, we highlight how these different orientations to global mindedness can be explicated via the narratives of the study participants, highlighting the sometimes subtle differences between them, but also how the outcomes of these variations can be significant when observing the practices they shape.

According to Beck, 'risk may be defined as a systematic way of dealing with hazards and insecurities introduced by modernisation itself ...' (1992: 21). Middle class parenting practices have been shown to involve various measures to assess and mitigate risks, in order to secure their children's future (Ball et al., 2013). If middle class groups are becoming more mobile, especially outside the borders of nation states, how much such forms of constant, instrumental or concerted, but also desired mobility across a more transnational space affect their assessment and mitigation of risk? Children's schooling is arguably disrupted during every move, new linguistic challenges might arise as families settle in new cities, and new social relations have to be forged (Favell, 2008). We are interested in how acts of family mobility affect parenting and education strategies, as well as conceptualisations of identity, belonging and futures among variously mobile middle classes.

\section{The Study}

For this study we deliberately sampled three distinctive groups of Jewish Israeli parents - Global Middle Class (GMC) (10 currently residing in Israel and 20 in London); 10 Israeli non-mobile Middle Class parents (MC) living in Tel Aviv; 28 Immigrant Middle Class (IMC), Israelis who had immigrated to London. In total 68 interviews were undertaken, and we have conceptualised the study as comprised of three distinct case studies (Yin, 2009).

We choose parents who met our criteria of mobility and socio-economic class group, and who had at least one school-age child. For GMC families, informants were recruited using the following criteria: at least one of the parents had to be working in a global industry (mainly multinational high tech firms 
in our case), were highly educated, travelled frequently for work, maintained close social relationships with people who lived abroad, had moved with their families at least once for a period of at least a year, and intended to move again. For IMC families we recruited parents who worked in white collar/professional jobs (for multinational firms, in Israel-related organisations in London, and civil society organisations), had at least one university degree, and moved permanently from Israel to the UK. While GMC families represent a relatively recent pattern of middle class families moving frequently, the IMC families in this research who had migrated from Israel to the UK for economic or political reasons (Yemini \& Maxwell, 2018a) represent a longer-term trend of post-world war migration. However, in the Israeli case - emigration from the new state of Israel is a relatively recent phenomenon (Gold, 2005). Finally, the MC families were recruited from the same neighbourhood and school, our GMC families currently residing in Tel Aviv were sampled from, thereby allowing us to compare practices around parenting and education for these two groups more closely (Yemini, Maxwell, \& Mizrachi, 2018). The Israeli-based MC parents were also university educated, worked in white collar/professional jobs such as the civil service, law and medicine. The participants across the three case studies were recruited via snowball sampling, starting with the personal connections of the second author, as well as via a closed Facebook group of Israeli mums in London. The interviews with parents in Tel Aviv were performed by our MA student, and in London, by the second author. Most participants were mothers (58 interviews) and 10 were fathers ${ }^{1}$.

Despite being a conflict-ridden and immigrant society, Israel maintains a globally competitive economy, and many of its citizens relatively financially secure (Yemini \& Fulop, 2015). A study by the Taub Center (Lahav, 2014) has categorised the Israeli middle class as consisting of two groupings based on their occupation and income levels; $40 \%$ of Israeli citizens belong to the lower middle class and $29 \%$ of the population belongs to the upper middle class. Many Israelis in the upper middle class are involved in the high-tech, law, and academic sectors and live in the Tel Aviv area (Bar, 2010). The present study focuses on this upper middle class group, those permanently living in Israel (MC), those temporarily based in Israel (GMC), those who have permanently immigrated to the UK (IMC) and those temporarily located there (another sample of the GMC). As such, this sample allows us to

\footnotetext{
${ }^{1}$ We did not found significant differences between the narratives created by the mothers and fathers in our study, despite the mothers taking a more prominent role in child-raising routines (Vincent, Braun, \& Ball, 2008). Given the relatively small sample of fathers, further comparative work would be needed to comment on this more comprehensively.
} 
consider more closely whether and how orientations to mobility might create differentiations between members of this same social stratum - the upper middle classes.

We undertook in depth interviews with all participants, examining the personal, educational and professional background of the parents, the educational choices made for their children throughout their lives, the after-school activities children currently attended, the kinds of family leisure activities engaged in, and what they anticipated for their children's futures. We also explored with parents reasons for travelling abroad for holidays, their approach to native and foreign language acquisition, and why they decided to immigrate and/or move for work (for IMC and GMC families). Interviews lasted between one to two-and-a-half hours, were conducted in Hebrew either in person or by video Skype, fully transcribed in Hebrew, and then some quotes translated into English. The data collection phase took place during 2017 and early 2018.

Informed by the grounded theory analytical approach (Strauss \& Corbin 1997), we analysed the data through constant comparison. The analysis procedure went through several distinct stages, including (1) open coding, in which through repeating interviews' reading and discussion we identified frequent topics; (2) axial coding, in which distinct themes were formed; (3) selective coding, in which we refined our themes; (4) theory formulation, in which we developed a hierarchy and shaped the final theoretical structure of our interpretation of the data. During this stage we combined our emic themes with etic categories that we had developed based on our literature review work which took place at the same time as our data collection and analysis endeavours.

In this paper, we present the three main themes that emerged during our analysis, namely: (a) differences in the boundaries of the space in which families were making parenting and educational choices; (b) the management of anxiety that might be generated by seeking to secure the best possible education and future opportunities for their children; and (c) the modalities of cosmopolitanism parents articulated during the narratives about their educational practices. We present and discuss these themes by focusing on four to five families from each of our three groups (GMC, IMC, MC), and connecting the concepts of mobility and cosmopolitanism (Beck, 2006) as we seek to examine how different forms of mobility may facilitate different modalities of cosmopolitanism.

We are aware of the uniqueness of our sample in terms their all stemming from one country of origin, but our paper is premised on the suggestion that we can arguably isolate the effect of different forms of mobility more easily if we reduce other differences in the characteristics of our sample. Thus, our 
intent is to develop more nuanced understandings of concepts that dominate the literature on the GMC, so they might be drawn on when studying other groups across a broader range of locations in future research.

\section{Differences in boundaries of 'the field'}

The literature on the educational strategies of the middle-classes emphasises how they seek to maximise the opportunities for their children to succeed through investing various resources in forms of cultivation practices that are concerted and concerned (Maxwell \& Aggleton, 2013). Whether such practices are driven by anxieties or a particular discursive construction of what middle-class parenting should constitute (Irwin \& Elley, 2013; Lopez Rodriguez, 2010), parents are making investments based on how they understand the 'field' (Vincent et al., 2012) in which they are trying to secure status and facilitate their children's future trajectories into. In our study, the different groups of middle-class parents are operating in quite different 'fields' - some connected to a certain nation state (in our case either Israel or the UK), but others operating across the boundaries of the nation state.

Our middle-class families (MC) living in Tel Aviv, find themselves tightly moored to life in Israel, and while being aware of 'the global', they make educational choices and seek to secure advantages for their children within a frame of reference that are still strongly bounded by the nation state. The parents we interviewed understood and were eager to support the nationally-developed markers of transition from childhood to adulthood that dominate Israeli society - serving in the Israel Defence Forces and attending Israeli higher education institutions. Sharon (MC mother) argued, "today, if you are not educated, didn't study at a university [with reference to Israeli universities], you cannot go anywhere; and yes, it is important to learn and to succeed." Meanwhile, Ella (MC mother) explained that one of the main priorities for her was to instil in her children, a "love of Israel...obviously they're going to serve in the Israel Defence Forces [IDF]. No question about it." Serving in the IDF has been linked to not only patriotic duties in strengthening and maintaining the Israeli state, but also proven to be critical in facilitating social networks which people later draw on in their professional lives (Swed \& Butler, 2015). Ultimately, Betty (MC mother) emphasised, that her parenting decisions were largely shaped by the overall desire that "I want them [the kids] to know that they will grow up and live here [in Israel] and their children and their grandchildren".

Our study helps raise the question about how parents, who immigrate and leave their nation state behind, understand the borders of the space in which they are seeking to educate and bring up their children. Here, their mobility has led them to bypass the borders of one nation state (Beck, 2012). As 
with many immigrants - these parents are seeking to transcend borders in order to make available to themselves and their children 'new beginnings' (Beck, 2006: 341).

"I don't care where they are going to live and what they are going to do in the future... as long as they are the best in it. They aim to the big world. This is why by the way we left Israel, so they would be able to think big". (Adi, IMC mother: moved from Israel to UK 10 years ago)

As Adi explains, the act of crossing the border of the nation state enables her and her children to "think big', in other worlds to think with a more global perspective and move beyond the parochialism of the state of Israel. Sonia (IMC mother: 2 years in the UK) adds, "diversity, this is the key word here; they learn how to succeed and the best thing in London is that you can meet people from all over the world - this what the world looks like". By moving to London, IMC parents revel in the opportunities their children have for encountering a rich diversity of peoples, learning how to speak English, and being able to apply to top British universities, as Sonia explained:

"Just to hear them chatting in English with this lovely accent. They are really gaining the best competency here. I will do everything to strengthen this. For my son, you almost can't tell that he is not English. Also for my daughter, but for the boy, absolutely...I wish I knew English as they do".

Developing such competencies in English, learning to engage with and live in a super diverse society (Vertovec, 2007), as well as being educated in the English schooling system, meant the IMCs felt their children could shape their future ambitions to fit with those accorded value both in the UK, but also more broadly in the world (such as applying to Oxbridge - Oxford or Cambridge - for university, or other internationally-recognised higher education institutions). The IMC parents in our sample inculcated the kinds of education strategies noted of the British middle class, such as a focus on the benefits of high status secondary schooling (Maxwell \& Aggleton, 2013), the importance of the right mix of students in schools (Reay et al., 2011) and how extra-curricular activities could signal particular accumulations of cultural capital (Vincent et al., 2013). Similar arguments have been made for other groups of skilled migrants coming to the UK (see for example, Ryan \& Mullholland, 2014), but critical to our argument is that the act of mobility to a new country, and settling there, re-directed the base from which they make choices around parenting and education, to better fit the values and anticipated success strategies of the new space/national boundaries they have entered. As Shahar (IMC mother: 1 year in the UK) explained: 
"We did some extensive research of where to live, the process of admission. I think that the education at home is what matters the most, but eventually you do think of secondary school and university. People from the neighbouring school do not end up at Oxford [university]".

The GMC parents in our research are also transcending borders in (a constant) search for new beginnings, as the IMC group were, but the differences in the form of mobilities engaged with, also helps to make sense of subtle differences in the education and parenting strategies the GMC articulated. The narratives of the GMC are replete with an ease and openness to the kinds of possible future trajectories their children might decide to pursue - that they could be anywhere in the world (including Israel).

"If they want to dance, they shall go to Julliard, and if they want to do marine biology, they will go to Sydney". (Efrat, GMC mother: Israel-USA-UK)

Lee (GMC mother: Israel-Switzerland-France-USA-Israel): "So in the US we also did the same as in Switzerland and in Israel with choosing schools for them. We asked people, there are lists and we wanted a good school. There when you go for the Jewish school, it is already of the better schools. So that is how we chose".

While Tom (GMC father: Israel-Switzerland-France-USA-Israel) continues:

"One of my sons wants to attend the Technion [Israeli Institute of Technology], and I hope that he gets in. My other son wants to attend Oxford. I hope he fulfils his dream too. Each one has his own aspirations. The important thing is that it be a good university, that the education there is good, that it prepares them. It doesn't matter where, or in which country... I want them to make a good living, so they reach the tops of their professions, in whatever career they choose, anywhere, and get the most out of their careers".

Key for GMC parents is that their children are learning the values and skills necessarily for such success.

"Yes, we are foreigners here, but it is OK for us. It is not that we are trying to get into those royal places to meet a prince. Once the kids have their values and capabilities they will be able to succeed. One day they can be in a posh English environment and the next day they can come back to Israel for the army service. We are very open to their wishes". (Zvia, GMC mother: Israel-US-UK) 
Due to their constant mobility, GMC parents understand that the critical space in which educating for success happens must be within the family. This realisation affects the kinds of schooling choices they make when moving to a new place. "This is not about OFSTED ratings [government inspection organisation for compulsory schooling]. Kids can experience great success in any school. In every country we choose a decent state school. We believe that the most important tools they are getting at home" (Ada, GMC mother: Israel-Singapore-Israel-UK). Thus, for parents like Ada, the criteria of the kinds of schools they select for their children are likely to be focused on the diversity they offer and the kinds of competencies this will facilitate for their children, rather than how particular educational institutions might facilitate access to elite forms of higher education in the nation state they are currently living in. This makes sense in light of GMC parents' desires for their children to study and live anywhere in the world, where national borders do not appear to constrain imagined future trajectories (Park, 2018).

"I believe that the best thing in this move is that the kids are becoming aware of the world. We are still very connected to the ongoing Israeli situation but here they learn to be entirely colourblind. They have a lot of Muslim friends and we instil in them those values... This is a big advantage for (developing) their identity". (Maya, GMC mother: Israel-Spain-UK)

Above we have highlighted how different middle-class families engage with the boundaries imposed by the nation state. The extent to which these groups cross and even transcend borders (as argued by Beck's cosmopolitan sociology) is shaped by the forms of mobility they practise. Locally-fixed middle class families envision futures that match their own limited mobility - one bounded by the nation state, where success is understood by drawing on the main markers that hold value in Israeli society - serving in the IDF, attending higher education afterwards and securing a professional future within their homeland, while using certain globally-oriented skills to strengthen their position in the field. Immigrant MC families, meanwhile, articulate how mobility has enabled them and their children to 'think big', i.e. beyond the nation state. Here - moving from their home nation to, in this case, the UK will help their children not only develop cosmopolitan skills and sensibilities - engagement with diversity, speaking good English - but also make them more competitive when seeking to apply to internationally-recognised, elite institutions of higher education - such as Oxbridge. For IMCs, their frames of reference have become global to some extent, but their educational choices are still bounded by the nation state to which they have immigrated - as is evidenced by their anxious deliberations about the school choices they make (see in the next section). Finally, the GMC parents involved in the study, mirroring their own mobile employment trajectories, suggest that all nation state borders can be transcended when articulating anticipated family mobility and their children's futures. Given 
the expectation of continued mobility - their current education choices focus on how to facilitate such constant mobility and instil in their children the skills and values they understand as central to success in the global space. In the next section we consider how confident parents appear about making available to their children opportunities that should guarantee future success.

\section{(Not)Anxious about the future}

We find substantial differences in the ways the middle-class fractions involved in our study engaged with risks and uncertainties. However, it was not amongst the GMC families that feelings of uncertainty are highest, as might have been predicted based on Beck's thesis. On the contrary, we suggest below that our GMC families, who have had significant experience of instability due to constant mobility that has characterised their professional lives, are more adapt at engaging with precarity because their proverbial muscles or orientations to practice have become trained to expect and proactively engage with uncertainty.

Beck argues that education becomes ever more important because ' ... the educated person incorporates reflexive knowledge of the conditions and prospects of modernity, and in this way becomes an agent of reflexive modernisation' (1992: 93). In other words, education (which is acquired through investment of efforts) is needed for success in professional sectors. Thus, the MC parents in our study stressed how "hard work" (Oscar, MC father) and continuous investment in education are critical in assuring their children's future success. Ben (MC father) declares: "The values of a desire to succeed, and ambition are important to me".

Oscar (MC father) agrees:

"I can tell you that its very, very important to me, I will support them financially, so they will go and learn as much as possible... I'm talking with them about this... From this age [three boys ages 2, 3, and 8 years] I teach them that a child should be educated, invest in studies already. If he does not invest from such age, he will not be accepted to the university".

Similarly, Yaron (MC father) claims:

"Except from English, where both of them being privately tutored, we invest in other activities too. It is all about persistence. He can end up in Olympics if persist"

Meanwhile, across the respondents who had immigrated from Israel to the UK, a different set of concerns were raised. In their narratives we see a much more concerned engagement with how best to 'invest' in the kind of education that will yield opportunities for success in the new system they have entered (Jarvinen \& Ravn, 2017). Thus, it is not hard work alone which will ensure advantages are accrued through education, but through the right choices made. As these IMC parents seek to make 
sense of how best to navigate the complexities of the English education space, they consider what forms of schooling are valued most highly. Shirley (IMC mother: 3 years in the UK) mused, "I read that all Oxbridge graduates come from private school, all the city people, the MPs, the judges". These impressions, while supported by data to some extent (Sutton Trust, 2012), indicate that schooling choices of new middle-class entrants into an education field draw on UK middle class markers, such as how "posh" people are and whether a school has "status". Thus Shahar (IMC mother, 1 year in the UK) confidently asserts:

"People from the neighbourhood school do not end up in Oxford ... in this school [the school they eventually chose for their children] all parents are very posh ... it is funny actually, but eventually if you are not born here, this is the only way to get the same status as one at home [i.e. attend a private school]".

The perception that over 30 percent of IMC's in our study had - that attending private school in England was the best guarantee of succeeding educationally - seemed to be based on the understanding that in English society the undefined concept of 'status' was central in signalling value (Podolny, 2008). This is significant given that only seven per cent of the English school-age population are private educated (Dearden et al., 2010). Shirley (IMC mother: 3 years in the UK) believed that, "for them [the English], it is not about the quality of the school, but rather about the status". Like some English middle-class parents (Reay et al., 2011), this particular understanding of how education worked in the UK put significant pressure on families, "I know we don't have enough money for private school but here they learn everything they will need"' (Sonia, IMC mother: 2 years in the UK).

Those IMC parents who could not afford to send their children to private school, invested time, drew on their networks and displayed persistency as they anxiously, but determinedly, sought to make the best choice for their children in the state system. Rosie (IMC mother: 4 years in the UK) explained:

"I got a recommendation, then started to follow some online discussions and we had some people who we knew already with kids at this school. The school didn't have a place for the girls and it seemed hopeless, but I worked in a very Israeli way, called them everyday, was really persistent and eventually we were moved up the (waiting) list. You can see how this school is different, they don't have uniform, the families are all from the same background, even one of the teachers first year was Jewish and helped us a lot".

When, as was often the case, their first choice of school was not immediately available, they found a 'holding' option, always with the intention of securing a place at the school they had determined would 
be best for their children, as was the case for Rosie - "we started at a Catholic school, which was better than others, because only certain people would come, and once we got the place [at our first choice school], we moved". Thus, the concerns and anxieties articulated by the IMC was less about how hard their children worked, but about having the right kinds of knowledge, financial resources and disposition to persist, in order to make the best schooling choices for their children.

The GMCs in our research, who currently lived in London or Tel Aviv, however, seemed less concerned about the type of school chosen. Ada (GMC mother: Israel-Singapore-Israel-UK) declared, "kids can experience a great success in any school. In every country we choose a decent state school. We believe that the most important tools they are getting at home". Similarly, Tali (GMC mother: Israel-US-Israel-UK) elaborated:

"Very soon I understood that with such a [mobile] lifestyle, I can't expect that Liah [her daughter] be outstanding in everything. Here there are different rules and things that are valued. I work a lot on her interpersonal skills. We meet plenty of friends during weekends and we go out for activities with her. Those are her truly meaningful experiences".

Thus, because every education system they moved to had different "rules and things that they value" (Tali), GMC parents invested in the kinds of values and skills their children developed as part of their mobile lives - one of which was a confidence about navigating periods of uncertainty as they settled somewhere new. As Zvia (GMC mother: Israel-US-UK) concluded, "the kids have their values and capability they will be able to succeed...". Important to note here is that the GMCs in our sample mostly choose to enrol their children in local, "good" schools - whether state or private - with only a minority using international schools, who offered the International Baccalaureate programmes.

Despite the lack of knowledge of the education systems they enter, and arguably a lack of clearly identifiable elite tracks through a global education system (Oh, 2018), the GMC in our study articulated a form of surety and assured optimism (Maxwell \& Aggleton, 2014). Within such spaces of uncertainty, the kinds of anchoring / stabilising footholds (Grzymala-Kazlowska, 2018) they lean on in order to navigate the education and future of their children are a form of transferable skills and experiential resources they believe will ensure their children succeed professionally and psychically. The discursive resources they draw on could be conceived of as a strategy for mitigating the risk either signalling a lack of anxiety about ensuring the future of their children, or masking over the frissons in their articulated confidence. Hadas (GMC mother, Israel-Kiev-Israel-Lisbon-London) declared, "we like this mobile style of life because the kids can grow up to become the citizens of the 
world. Not just getting great grades or something". The "or something" signals a dismissal of the anxieties associated with middle-class parenting. Hadas positions the 'family' as the critical institution in which success is defined and that will sustain the development of the kinds of future subjects they have value: "we are looking for multicultural experiences, for doing things the way kids remain interested in learning, the grades are not important for us as a family".

We suggest therefore that differently located middle-class families conceive of 'risk' in relation to their role as parents in educational choice-making in various ways, and that articulated uncertainties and mitigating strategies are shaped by the type of mobility engaged in. In the next section we consider more closely the nature of the 'multicultural' experiences different middle-class families are seeking, the values and skills they want their children to embody, and how parental education strategies seek to facilitate this.

\section{The nature of cosmopolitanism}

All families understood middle-class futures as having to engage with 'the global' to some extent through work (employed by, collaborating or trading with companies in other countries), through travel (for leisure, immigration, work), through meeting people from other parts of the world, and appreciating the criticality of English as a common language to communicate through. Such reference points can be associated with various articulations of cosmopolitan capital (Igarashi and Saito, 2014; Szerszynski \& Urry, 2006; Weenink, 2008). While debates about the meaning of cosmopolitanism and its various articulations continue (Beck \& Szhaider, 2006), and scholars consider whether it is a form of cultural capital, a capital in and of itself, or something that can become more embedded within the habitus (Maxwell \& Aggleton, 2016), we have found Andreotti et al.'s (2015) conceptualisation of global mindedness as a multi-dimensional concept that denotes various 'modes of existence and exposure' (p. 246) particularly fruitful for our analysis. In the following we show how Andreotti's et al.'s (2015) model echoes the dispositions towards cosmopolitanism held by the three groupings in our sample.

"We make sure to travel with them [the children] from a very young age, going on trips abroad, and of course within Israel as well. In Israel we go off on a regular basis, but also at least once a year we go abroad as well. The last trip was a trip to the Far East, to the third world, to Vietnam and Thailand, because I think it's very important, and even if they do not remember anything (and my little ones will not for sure) it teaches them that the world is big and there are many kinds of people, many ways to live a life. Some people look different, and make you 
feel different, that you are suddenly in a different place, I think that is important to the child" (Betty, MC mother).

Betty's description of their holiday plans and the articulated rationale for such trips abroad, mirror closely Andreotti et al.'s (2015) disposition of the 'tourist'. Here, Betty suggests that the cultures of countries in various 'third world' can be understood homogenously as a singular entity, that can be experienced and understood as different to one's own. Learning to experience difference and to be comfortable with difference is positioned here as an important part of a middle-class children's education.

In order to learn how to navigate difference and be tourists in other parts of the world (whether for leisure or as a necessary skill when conducting business with people in other parts of the world in the future), English emerged as a core competency local middle class parents in Israel wanted to gift their children. Ella (MC mother) emphasized, "I am very strict on them with the English private tutoring, both of them regularly attend (private lessons)...I see how important it is nowadays, and here in our neighbourhood there are many kids who have a very high level of English". Ella's narrative is suggestive of the strategic investments and of hard work noted in the section above, which characterise the way locally-bounded middle class parents discussed educational strategies necessary to meet future aspirations. The abilities and additional advantages of others around them - in their relatively homogenous bubbles of middle-class Tel Aviv neighbourhoods (Oplatka, 2002; Maxwell \& Aggleton, 2010) - also appears to drive their concerns to focus on English as a necessary resource for the future.

The IMC parents in our study also valorise significant competency in English as one of the benefits of immigrating from Israel to the UK. For the IMC parents, becoming fluent English-speakers is perhaps a fortunate consequence of their mobility from Israel to the UK. The emphasis for this fraction of the middle-class studied is on a form of empathetic global mindedness or cosmopolitanism. In such an articulation, according to Andreotti et al. (2015), there is an acknowledgement that we can all have different perspectives and we should be seeking to understand the world from other's standpoints. Our empathetic disposition allows us to act as a bridge between cultures or even to fuse across difference. As Morin (IMC mother: 3 children, 12 years in the UK) describes:

"[We] want them to see the world as open to them; be able to communicate, be able to feel comfortable in this diversity, when they travel, when they meet people at work. Really engage with the world in all their senses".

Here, Morin suggests an 'open'-ness to, and keen engagement with, diversity that is infused with 'comfort'. Viki (IMC mother: 2 years in the UK) elaborates: 
"I asked them to get to know more kids. We have this adorable Chinese boy who is a good friend of my son's. So one day you will find us having a playdate with girl from Sudan and and a boy from China and all of them getting along together so nicely. This is exactly the type of education we are aiming for. In Israel, you can [only] see the same families of the same kind".

Being able to manage difference, bridge across cultures, 'getting along ... nicely' emerged as a significant narrative arc in the stories of those Israeli middle class families who had chosen to leave Israel.

Meanwhile, the members of the GMC embraced diversity, expected their children to become fluent in English but articulated a disposition to the global that was subtly yet critically different to our IMC group. Through constant mobility, adapting and adjusting to new places of residence and new schools (which were local, and state-funded in the main), GMC families are seeking to develop a form of 'visiting' global mindedness or cosmopolitanism amongst their children. Mobility opens up opportunities for their children to learn to live in different worlds and understand that geography and culture shape how people engage with space and one another. The discomfort such re-location engenders is embraced, which facilitates a confidence about navigating the 'unscripted' encounter with others and difference (Andreotti et al., 2015).

"This is exactly the type of values that we are working on providing for them ... this is what will make then resilient, ready to enter the world. They can live anywhere, be whatever they want, but will not have to worry about their values". (Zviah, GMC mother: Israel- Switzerland-UK) Here, Zviah re-emphasises the points made above about the GMC, that parents see it as their role to develop certain orientations within their children, and that the opportunities of mobility are significant in shaping future possibilities ('they can live anywhere, be whatever they want'). Furthermore, as argued in the previous section, the GMC parents suggest a high degree of surety about their children's abilities to pursue such futures and be successful. Though, in order to facilitate this their children must develop a resilience and a set of values (both fairly nebulous concepts) that will make this possible. Though not specifically defined by the parents as such, if we draw on Andreotti et al.'s (2015) idea of 'visiting', one could understand the dispositions being encouraged by the GMC parents as characterised by an openness and desire to locate oneself in different places in the world, which in turn would facilitate the development of a form of resilience to manage the discomfort and uncertainty experienced when moving from one space to another. It is this skill and malleability that GMC families appear to forefront in their parenting and educational strategies. Rachel (GMC mother: Israel-Spain- 
UK) explained: "we need to open up as many possibilities as possible around [access to] information, curiosity, personal development, to change...(our emphasis)". This was confirmed by Tzvika (GMC father): "Like I said, this is a global world and I really want the world to be open for them. They have all the things (values) from here, with hiking every week and knowing Israel and then they do the same in other places. You need this to have the world open to you".

Conceptualising the kinds of global mindedness or cosmopolitan dispositions of the GMC in our research in this way, also allows us to suggest why this middle class fraction appeared so confident in their navigation around the world, transcending borders of the nation state and continually making school choices in new contexts. Through understanding their movement across space as a form of 'visiting', where the expectation is to embed oneself without hesitation in a new space and engage with enthusiasm in unscripted encounters - such a discursive setting shapes the affective outcomes of such interactions, in this case - positively, which in turn promotes agentic and assured practices (Maxwell \& Aggleton, 2014; Yemini \& Maxwell, 2018a).

\section{Conclusion}

Studies of middle class parental education strategies can be found across the world. Similarly, the school choices of middle class migrants have been closely researched in numerous global locations (see Ryan \& Mulholland, 2014, for instance). Meanwhile, the concept of the globally mobile professional (Erkmen, 2015; Beaverstock, 2018) and global middle class(es) (Ball \& Nikita, 2014; Yemini \& Maxwell, 2018b) has been theoretically introduced, but much less empirically investigated. In this contribution we have sought to closely examine how family mobility for parents' professional lives shapes parenting and education strategies. By comparing similarly educated, same-nationality middle class groups, who are distinguished by the form of mobility engaged in, we have been able to advance nuanced but critical differences in their orientations to schooling and future-making.

We demonstrated that family mobility shapes conceptualisations of the geographical borders of the spaces in which they are making choices - around schooling, futures and relations to Others. The MC remain moored within national borders, the IMC shift their fields of orientation to the new nation state they occupy, while the GMC appear to actively transcend geographic borders. A second aspect differentiating our middle class participants was the nature of the uncertainties shaping parents' narratives. The locally-moored MC focused on ensuring their children demonstrated a commitment to hard work, learning English and following the relatively traditionally-acknowledged tracks to creating successful futures in Israeli society (such as serving in the Israeli Defence Force, attending 
higher education institutions and appropriate extra-curricular activities). These parents knew what was needed, so focused on investing the time needed to realise these. Meanwhile, the IMC were excited by the opportunities offered by their move from one country to another in terms of acquiring English skills, learning to reach across cultural and ethnic divides, but also articulated an anxiety about having to navigate an education system where financial resources were more likely to secure the kinds of education and credentials that would ensure their children's future opportunities to access elite higher education and professions. Finally, the GMC parents' narratives appeared to be much less anxious in tone. Participants in this group appeared unconcerned by the kinds of status different forms of education were accorded across countries, and secure in their belief that they could facilitate the development of particular kinds of cosmopolitan values and skills necessary for future success within the family. To appreciate why this is viewed as a successful strategy by the global middle classes, we integrated Andreotti et al.'s (2015) multi-dimensional understanding of global mindedness to analyse the nuanced articulations of cosmopolitanism and how different middle class fractions draw on these resources in their education strategies for success. In the context of this Special Issue, we show that GMC families foster quite unique ways of preparing their children to engage with uncertainty, risk and continuous geographic mobility, which could be understood as a particular characteristic of this social class fraction. Our contribution also highlights how articulations of cosmopolitanism by the GMC, at least, combine instrumental and humanistic modalities of cosmopolitanism as critically working in tandem (rather than in opposition as often positioned in the literature).

Lopez Rodriguez (2010) asks in her study of migrant Polish mothers in England, 'is it in fact this precariousness and risk awareness which gives rise to their instant adaptability and compels them to harvest all that they need, almost for survival' (p. 347). We found evidence of such a disposition in our GMC participants, yet with a much less affectively anxious tone of 'survival'. The GMCs' embracement of uncertainty and prioritisation of adaptability across spaces as an orientation to foster within their children, appears quite different to the more 'usual' middle class parenting and educational strategies found in our IMC and MC families. Yet, mobility outside of one space to another, also effects the kinds of futures envisaged by, and educational priorities parents have, thus differentiating our IMC from the MC sample. We argue that different types of mobilities should be understand as being driven by, and in turn encouraging different modalities of cosmopolitanism to be embodied, which, in turn, affect the parenting and education strategies of the middle classes. 


\section{References}

Andreotti, V., Biesta, G., \& Ahenakew, C. (2015). Between the nation and the globe: Education for global mindedness in Finland. Globalisation, Societies and Education, 13(2), 246-259.

Appiah, K. A. (2006). Cosmopolitanism: Ethics in a world of strangers (issues of our time). New York and London: WW Norton \& Company.

Ball, S. J., \& Nikita, D. P. (2014). The global middle class and school choice: A cosmopolitan sociology. Zeitschrift für Erziehungswissenschaft, 17(3), 81-93.

Ball, S. J., Rollock, N., Vincent, C., \& Gillborn, D. (2013). Social mix, schooling and intersectionality: Identity and risk for Black middle class families. Research Papers in Education, 28(3), 265-288.

Bar, A. (2010). The characteristics of the middle class in Israel and an analysis of the changes that have taken place in recent years. Jerusalem: The Knesset Research and Information Center. Retrieved from https://www.knesset.gov.il/mmm/data/pdf/m02671.pdf (Hebrew).

Bauman, Z. (1998). Globalization. The human consequences. Cambridge: Polity Press.

Beaverstock J. (2018) New insights in reproducing transnational corporate elites: the labour market intermediation of executive search in the pursuit of global talent in Singapore. Global Networks, online 19 April.

Beck, U. (1992). Risk society: Towards a new modernity. London: Sage.

Beck, U. (2006) The cosmopolitan vision. Cambridge: Polity Press.

Beck, U. (2007). The cosmopolitan condition: Why methodological nationalism fails. Theory, Culture \& Society, 24(7-8), 286-290.

Beck, U. (2012). Redefining the sociological project: The cosmopolitan challenge. Sociology, 46(1), 7-12.

Beck, U., \& Sznaider, N. (2006). Unpacking cosmopolitanism for the social sciences: A research agenda. The British Journal of Sociology, 57(1), 1-23.

Brown, W. (2010). Walled states, waning sovereignty. New York: Zone books..

Cohen, N. (2011). Rights beyond borders: Everyday politics of citizenship in the Israeli diaspora. Journal of Ethnic and Migration Studies, 37(7), 1137-1153.

Dearden, L., Ryan, C. and Sibieta, L. (2010). What determines private school choice? A comparison between the UK and Australia. IFS Working Papers (10/22).

Erkmen, T. D. (2015). Houses on wheels: National attachment, belonging, and cosmopolitanism in narratives of transnational professionals. Studies in Ethnicity and Nationalism, 15(1), 26-47.

Gaudelli, W. (2016). Global citizenship education: Everyday transcendence. London: Routledge.

Grzymala-Kazlowska, A. (2018). From connecting to social anchoring: adaptation and 'settlement'of Polish migrants in the UK. Journal of Ethnic and Migration Studies, 44(2), 252-269.

Gold, S. J. (2005). The Israeli Diaspora. London: Routledge.

Goren, H., Maxwell, C., \& Yemini, M. (2018). Religion, marginalisation and economic globalisation - Teachers make sense of global citizenship education in a divided society. Comparative Education, $1-20$.

Hannerz, U. (2007). Foreign correspondents and the varieties of cosmopolitanism. Journal of Ethnic and Migration Studies, 33(2), 299-311. 
Igarashi, H., \& Saito, H. (2014). Cosmopolitanism as cultural capital: Exploring the intersection of globalization, education and stratification. Cultural Sociology, 8(3), 222-239.

Irwin, S., \& Elley, S. (2013). Parents' hopes and expectations for their children's future occupations. The Sociological Review, 61(1), 111-130.

Järvinen, M., \& Ravn, S. (2017). Playing the game or played by the game? Young drug users' educational trajectories. British Journal of Sociology of Education, 1-14.

Kenway, J., Fahey J., Epstein D., et al. (2017) Class Choreographies. Elites Schools and Globalization, Basingstoke: Palgrave Macmillan.

Lahav, L. (2014, May 23). Research: There is a middle class and there is a middle class. Yedioth Ahronoth Y-net. Retrieved from http://www.ynet.co.il/articles/0,7340,L-4521857,00.html (Hebrew).

Lopez Rodriguez, M. (2010). Migration and a quest for 'normalcy'. Polish migrant mothers and the capitalization of meritocratic opportunities in the UK. Social identities, 16(3), 339-358.

Maxwell, C., \& Aggleton, P. (2016). Creating cosmopolitan subjects: The role of families and private schools in England. Sociology, 50(4), 780-795.

Maxwell, C. \& Aggleton, P. (2014) 'Agentic practice and privileging orientations among privately educated young women', The Sociological Review, 62(4): 800-820.

Maxwell, C., \& Aggleton, P. (2013). Becoming accomplished: Concerted cultivation among privately educated young women. Pedagogy, Culture \& Society, 21(1), 75-93.

Maxwell, C. \& Aggleton, P. (2010) 'The bubble of privilege. Young, privately educated women talk about social class', British Journal of Sociology of Education, 31(1): 3-15.

Oh, H. J. S. (2018). Escaping obsolescence? The shift from subject to skill based education in a South Korean international school. Discourse: Studies in the Cultural Politics of Education, 1-15.

Oplatka, I. (2002). The emergence of educational marketing: Lessons from the experiences of Israeli principals. Comparative Education Review, 46(2), 211-233.

Park, J. (2018). Public fathering, private mothering: Gendered Transnational Parenting and Class Reproduction among Elite Korean Students. Gender \& Society, 0891243218771551.

Podolny, J. M. (2008). Status Signals. A Sociological Study of Market Competition, Princeton, NJ: Princeton University Press.

Reay D, Crozier G and James D. (2011) White Middle Class Identities and Urban Schooling, Basingstoke: Palgrave Macmillan.

Rizvi, F. (2005). International education and the production of cosmopolitan identities. Transnational Seminar Series, Champaign, University of Illinois at Urbana-Champaign.

Ryan, L., \& Mulholland, J. (2014). 'Wives are the route to social life': An analysis of family life and networking amongst highly skilled migrants in London. Sociology, 48(2), 251-267.

Scott, S. (2006). The social morphology of skilled migration: The case of the British middle class in Paris. Journal of Ethnic and Migration Studies, 32(7), 1105-1129.

Schiller, N. G., \& Irving, A. (Eds.). (2014). Whose Cosmopolitanism?: Critical Perspectives, Relationalities and Discontents. Berghahn Books.

Sheller, M. \& Urry, J (2006). Mobilities, immobilities and moorings. Mobilities, 1(1), 1-22.

Strauss, A. L., \& Corbin, J. (Eds.). (1997). Grounded theory in practice. London: Sage. 
The Sutton Trust (2012). The Educational Backgrounds of the Nation's Leading People. London: Sutton Trust.

Swed, O., \& Butler, J. S. (2015). Military capital in the Israeli Hi-tech industry. Armed Forces \& Society, 41(1), 123-141.

Szerszynski, B., \& Urry, J. (2006). Visuality, mobility and the cosmopolitan: inhabiting the world from afar. The British Journal of Sociology, 57(1), 113-131.

Vertovec, S. (2007). Super-diversity and its implications. Ethnic and Racial Studies, 30(6), 1024-1054.

Vincent, C., Braun, A., \& Ball, S. J. (2008). Childcare, choice and social class: Caring for young children in the UK. Critical Social Policy, 28(1), 5-26.

Vincent, C., Rollock, N., Ball, S., \& Gillborn, D. (2012). Being strategic, being watchful, being determined: Black middle-class parents and schooling. British Journal of Sociology of Education, 33(3), 337-354.

Vincent C, Rollock N, Ball S, et al. (2013). Raising Middle-class Black Children: Parenting priorities, actions and strategies. Sociology, 47(3), 427-442.

Urry, J. (2007). Mobilities. Cambridge: Polity.

Weenink, D. (2008). Cosmopolitanism as a form of capital: Parents preparing their children for a globalizing world. Sociology, 42(6), 1089-1106.

Yemini, M., \& Maxwell, C. (2018a). De-coupling or remaining closely coupled to 'home': educational strategies around identity-making and advantage of Israeli global middle-class families in London. British Journal of Sociology of Education, 1-15.

Yemini, M., \& Maxwell, C. (2018b). Discourses of Global Citizenship Education: The Influence of the Global Middle Classes. The Palgrave Handbook of Citizenship and Education, 1-14.

Yemini, M., Maxwell, C., \& Mizrachi, M. (2018). How does mobility shape parental strategies: a case of the Israeli global middle class and their 'immobile' peers in Tel-Aviv. Globalisation, Societies \& Education, 1-20.

Yemini, M., \& Fulop, A. (2015). The international, global and intercultural dimensions in schools: An analysis of four internationalised Israeli schools. Globalisation, Societies and Education, 13(4), 528552.

Yin, R. K. (2009). Case study research: Design and methods (4th ed.). Thousand Oaks, CA: Sage. 